\title{
Precarização do trabalho e desproteção social: desafios para a saúde coletiva
}

\author{
Insecurity in the labor market and lack of social \\ protection: challange for collective
}

Carlos Minayo Gomez 1

Sonia Maria da Fonseca Thedim-Costa 1

\footnotetext{
1 Centro de Estudos da Saúde do Trabalhador e Ecologia Humana, Escola Nacional de Saúde Pública, Fundação Oswaldo Cruz. CESTEH/ENSP/Fiocruz, Av. Leopoldo Bulhões, 1480, Manguinhos, 21041-210, Rio de Janeiro, RJ, Brasil
}

\begin{abstract}
This study presents a characterization of insecurity in the labor market, affecting great parts of the Brazilian society. We discuss some dimensions of this conjuncture resulting from the structural systems and the opening of ecomomy on international basis. We state the socio-political consequences of these changeswhich are representing the new social question. This degradation of the life standard, of production systems, associated with the lack of social protection takes form in a desintegration/ reconstruction of identities created in turn of labor. The violence in the big urban centers worsen the range of contradictions of the contemporaneous life, constituting malig effect of these transformations. The repercussions for health are the heart of the problem. In view of the difficulty of collection and measurement of indicators for the implications of this picture through the usually employed means one invested in the construction of methodological strategies which enable us to formulate estimates of the damage caused to health, resulting from the current process of introduction/exclusion from work. We still describe three of the actions carried out in public health services, with adolescents in extreme risk situations and in police stations, analysing the records.

Key words Insecurity in the Labor Market; Social Exclusion; Work Accidents; Social Violence
\end{abstract}

Resumo Apresenta-se uma caracterização das manifestações atuais da precarização do trabalho que vem atingindo amplos setores da população brasileira. Discutem-se dimensões da reestruturação produtiva, da integração mundial dos mercados financeiros e da internacionalização e abertura das economias. Enunciam-se conseqüências politico-sociais das mudanças que configuram a nova questão social. No caso brasileiro, observa-se progressiva pauperização que envolve inclusive trabalhadores integrados ao mercado formal de trabalho, gerando insegurança, instabilidade e precariedade nos vínculos laborais e desestruturação/reconstrução de identidades geradas em torno do trabalho. A violência urbana vem agravar o conjunto de contradições da vida contemporânea. As repercussões para a saúde situam-se no cerne dessa problemática. Diante da dificuldade de apreender e dimensionar, com o instrumental habitualmente utilizado, as implicações desse quadro, investiu-se na construção de estratégias metodológicas capazes de fornecer subsídios para formular estimativas dos agravos à saúde. Descrevem-se três dos investimentos realizados em serviços públicos de saúde, junto a adolescentes em situações extremas de risco e em delegacias policiais, onde foram analisados os registros de ocorrências.

Palavras-chave Precarização do Trabalho; Exclusão Social; Acidentes de Trabalho; Violência Social 


\section{Introdução}

As profundas transformações do modelo econômico decorrentes da reestruturação produtiva, da integração mundial dos mercados financeiros, da internacionalização das economias, da desregulamentação e abertura dos mercados, com a quebra de barreiras protecionistas, em suas causas e conseqüências político-sociais, vêm atingindo, de forma acelerada e diferenciada, sobretudo na última década, amplos setores da população trabalhadora. Essas mudanças, em grau e extensão diferentes entre países e no interior dos mesmos, geram permanentes incertezas, novas tensões, aprofundamento das desigualdades sociais e da exclusão social.

No caso brasileiro, observa-se um processo de pauperização, inclusive entre os trabalhadores integrados ao mercado de trabalho, como resultado de uma trajetória marcada pela insegurança, instabilidade e precariedade nos vínculos laborais. Essa degradação das condições materiais de vida, das formas de reprodução, agravada pela ausência de mecanismos de proteção social e associada à desestruturação/reconstrução de identidades geradas em torno do trabalho, configura, em sua complexidade, a nova questão social.

A violência nas grandes metrópoles expressa em formas e espaços distintos, vem agravar o conjunto de contradições da vida contemporânea, constituindo-se em mais um efeito nefasto dessas transformações. As repercussões para a saúde, de natureza diversa, situamse no cerne dessa problemática que afeta os trabalhadores ainda inseridos no mercado formal, sobretudo os terceirizados, mas refletese, particularmente, no grande contigentes de excluídos e em segmentos mais vulneráveis do mercado informal, em contínua expansão. Dentre estes, os que exercem atividades com expressivo impacto nas taxas de morbi-mortalidade, não contempladas nos estudos sobre o trabalho informal, por razões que vão desde a falta de reconhecimento social a seu caráter de ocupação à margem da legalidade.

Diante da dificuldade de apreender e dimensionar tais implicações com o instrumental habitualmente utilizado, investiu-se na construção e operacionalização de estratégias metodológicas capazes de subsidiar a formulação de estimativas dos agravos à saúde, concebidos em sua amplitude, mas em particular relacionados ao o trabalho e ao não-trabalho.
Para tanto, recorreu-se a fontes de informação que, apesar de suas limitações, permitem ultrapassar as estatísticas da Previdência Social, reconhecidamente incompletas e restritivas. Paralelamente, foram desenvolvidos, junto a grupos determinados, estudos empíricos, de caráter qualitativo que, além de ampliar a base de informação, revelam um conjunto de significados atribuídos pelos sujeitos à relação entre a especificidade de seu trabalho e os danos sofridos.

\section{Reestruturação produtiva e precarização do trabalho}

O movimento de globalização econômica se caracteriza pela grande mobilidade de massas de capitais, pelo crescimento de corporações transnacionais e pela predominância dos investimentos no âmbito financeiro, onde acontece a maior valorização do capital, inclusive por corporações industriais ou de serviços. Os fluxos financeiros mundiais são de tal ordem que correspondem hoje a aproximadamente 78 vezes dos recursos aplicados produtivamente Pochmann (1999). Em conseqüência, acelera-se a internacionalização das grandes decisões - das quais o trabalhador enquanto ator social, tem estado sistematicamente alijado com a concomitante redução do papel dos Estados nacionais na obtenção de recursos tributários e na formulação e efetivação de políticas. Por outra parte, os imperativos do crescimento econômico e da competitividade no mercado regem a alteração radical do paradigma produtivo. Uma lógica de flexibilização das estruturas produtivas e das formas de organização e divisão social do trabalho intra e inter-empresas, intensifica o fenômeno visível da fragmentação e da dispersão dos processos produtivos por várias nações, através de filiais, empresas fornecedoras, subcontratadas. Além de visar ao aproveitamento mais eficiente das tecnologias e matérias primas existentes para um mercado consumidor global, implanta-se também um processo de flexibilização da força de trabalho. De acordo com as conveniências e conjunturas locais, estabelecem-se variadas formas de contratação: desde vínculos estáveis nos moldes convencionais ou com diversos níveis de precarização que conformam os denominados empregos atípicos Caire (1997) - terceirizados, temporários, em tempo parcial, por tarefas - até a utilização da 
mão-de-obra familiar, o que conduz a uma alternância entre emprego e não-emprego.

As críticas à rigidez do modo de produção fordista, considerada fator limitante do crescimento, justificam a tendência mundial de exacerbar uma flexibilização, fundada em duas premissas concomitantes e interligadas. Por um lado, fomentam-se variáveis de produtividade, buscando a qualidade total de processos e produtos. Incrementam-se inovações tecnológicas como elementos-chave para enfrentar a competição mundial ou realizam-se reformas organizacionais, sem investimentos substanciais em novas tecnologias, com o intuito de obter os mesmos resultados a custos mais reduzidos. Tendo como foco as demandas do cliente e as flutuações do mercado, adota-se a estratégia de obter produtos de qualidade, em curto prazo de tempo, aliada a políticas de treinamento, de capacitação profissional e de proteção social, que redundem no aprimoramento da organização do trabalho, com profissionais de elevado nível de formação e remuneração. Opostamente, estabelecem-se contratos de trabalho precários, subcontratação em cascata configurada por uma externalização de riscos e responsabilidades, com redução de salários e de empregos.

A circulação mundial de capitais produtivos baseia-se fundamentalmente nos potenciais de mercado, de recursos naturais, de capacitação estratégica e na busca de eficiência por meio de investimentos em pesquisa e desenvolvimento nos países avançados. Os capitais produtivos dirigem-se, potanto, para zonas onde a força de trabalho, apesar de cara, é altamente qualificada, polivalente, com um repertório de habilidades para adaptar-se às flutuações da demanda e que têm condições de comercialização e infra-estrutura de telecomunicações, bem como de manutenção de equipamentos sofisticados. Em contrapartida, voltam também seus investimentos para regiões onde o trabalho é barato, com inferior conteúdo tecnológico, mas com utilização intensiva de matéria prima e mão-de-obra.

Esse quadro de reestruturação das empresas e dos sistemas produtivos, inquestionável numa ótica eminentemente econômica, acarreta um pesado ônus expresso, em última instância, na precariedade e na exclusão social, fontes alimentadoras da violência atual. Uma precarização que atinge não apenas as populações consideradas vulneráveis, mas o conjunto da sociedade, embora de modo diferen- ciado, muitas vezes sob o eufemismo de novas formas de trabalho. Essa figura semântica - que aparentemente revela um avanço nos parâmetros tradicionais de exercício profissional - esconde, no entanto, a diminuição de postos de trabalho e a fragilidade dos novos arranjos laborais como a oferta de empregos de tempo parcial ou duração eventual; as limitações na absorção da força de trabalho jovem, inclusive qualificada; a instabilidade e irregularidade ocupacionais; o subemprego e o desemprego recorrente, duradouro e sem perspectivas de inclusão no mercado formal; as dificuldades de inserção da mão-de-obra não-qualificada e os rendimentos decrescentes para boa parcela das populações já empobrecidas

Precarização econômica e regressão social convergem com a omissão do Estado em funções fundamentais no âmbito do trabalho e da proteção social. Nesse contexto, questiona-se a legitimidade de um Estado que, pautado pela racionalidade da ordem econômica dominante, ausenta-se na redefinição das regulações contratuais e salariais anteriores e nem mesmo consegue desempenhar seu papel na compensação das desigualdades e fragilidades sociais, bem como na reparação das injustiças. Um Estado que, frente ao enorme contingente do moderno "exército industrial de reserva" gerado pelo desemprego em massa, oferece, quando muito, alternativas de re-inserção circunstancial negociadas com as empresas, por meio de incentivos financeiros e redução ou isenção de encargos sociais.

\section{A nova questão social}

Encontramo-nos hoje perante a nova questão social, cuja amplitude e centralidade se assemelham às suscitadas pelo pauperismo da primeira metade do século XIX, como afirma Castel, para quem " no momento em que os atributos vinculados ao trabalho para caracterizar o status que situa e classifica um indivíduo na sociedade pareciam ter-se imposto definitivamente, em detrimento de outros suportes da identidade, como o pertencimento familiar ou a inscrição numa comunidade concreta, que essa centralidade do trabalho é brutalmente colocada em questão enquanto sentido da experiência humana, inclusive como fator associado ao crescimento. Teremos chegado a uma quarta etapa de uma história antropológica da condição de assalariado, etapa 
em que uma odisséia se transforma em drama?” Castel (1998). A precarização, o não-trabalho, é mais do que o desemprego. Como avalia o próprio autor, evocando Hannah Arendt, mesmo sem desconhecer o frágil equilíbrio das décadas prededentes, é o reaparecimento de um perfil de "trabalhadores sem trabalho", os quais ocupam na sociedade, literalmente, um lugar de supranumerários, de "inúteis para o mundo". E que vêm engrossar o contingente populacional, por vezes "funcional", das "massas desarraigadas", dos grupos "considerados supérfluos” Arendt (1990), sem espaço na vida econômica, na produção de bens e serviços, com reduzidos direitos sociais e humanos. Uma força de trabalho atomizada, desprotegida socialmente, por cujo infortúnio ninguém parece ser responsável, restando-lhe apenas soluções individuais. Essa fragilização ou ruptura de vínculos comporta privação econômica e reverte em profundo isolamento.

O senso de solidariedade que distinguia os movimentos de trabalhadores organizados está em declínio. As negociações coletivas voltam-se prioritariamente para os trabalhadores do quadro funcional das empresas e as reivindicações têm como foco central a manutenção do emprego e o posicionamento frente às propostas de redução da jornada de trabalho, com a conseqüente diminuição de salário, como alternativa de incorporação, sob contratos precários, de mão-de-obra desempregada. Os próprios interesses dos trabalhadores terceirizados, submetidos às mais desfavoráveis formas de contratação e de condições de trabalho, raramente são contemplados.

Atualmente o questionamento da exploração econômica, do trabalho-mercadoria, dos moldes tayloristas e fordistas de produção, tornou-se anacrônico diante da necessidade de manter o emprego e da urgência em formular estratégias que propiciem a inserção, sem maiores indagações, de segmentos da população desempregada ou com precária situação laboral.

A vulnerabilidade inerente às diversas faces da precarização tem como desfecho final o desemprego recorrente, a exclusão social. Uma exclusão caracterizada "por trajetórias de labilidade dos vínculos sociais até uma ruptura completa, atravessando "terrenos" de dissociação ou desvinculação. Entre o início da trajetória e a ruptura total, existem situações (ou zonas) intermediárias de rupturas parciais de vínculos, eventualmente reconstituídas a partir da criação de novos vínculos mais ou menos lábeis” Escorel (1999). Nos países centrais, mecanismos públicos de bem-estar social e redes de proteção social amenizam essas situações e impedem, em alguma medida, que a exclusão social se consuma em todo seu potencial desagregador. Em países periféricos, como o Brasil, sua principal dimensão é a contínua e crescente aproximação do empobrecimento.

A exclusão social, em sua configuração multifacetada, manifesta-se na subtração de direitos humanos fundamentais, como o trabalho regular, condignamente remunerado, e a educação formal progressiva de crianças e adolescentes impelidos a ingressar precoce e precariamente no trabalho. Implica a negação da equidade, da justiça e da cidadania, dando origem a um amplo leque de categorias excluídas.

A gravidade da precarização e do desemprego, quando instalados, está na tendência a se perpetuarem, dada a ausência de alternativas previsíveis. Passam a fazer parte da dinâmica de erosão de uma modernidade que aponta para a desagregação da sociedade do trabalho e do modelo do Estado do bem-estar social, cujas bases de sustentação pressupunham o pleno emprego, a estabilidade e a seguridade social. Não cabe esperar que a lógica do livre jogo das regras do mercado possibilite reabsorver essa população deslocada, à margem de qualquer sistema previdenciário. Competividade e rentabilidade não combinam com solidariedade e coesão social. Enfrentar o acelerado crescimento de contingentes ocupacionais economicamente desnecessários e supérfluos que ampliam as dimensões do desemprego estrutural, sem a menor chance de acesso ou reingreso a postos de trabalho, sem espaço na vida econômica, é o maior desafio imposto pelo fenômeno da exclusão. Essas mudanças colocam em questão as bases futuras dos sistemas democráticos. Trata-se de uma crise de mutação civilizatória que elimina as perspectivas de inserção pela via do trabalho Forrester (1997). A autora condena a hipocrisia de políticos e governantes ao prometerem reiteradamente a superação da crise e a ampliação do mercado de trabalho. Considera falacioso querer impor a inserção social através do vínculo com o mundo do trabalho quando, na prática, ela é negada porque deixou de existir.

Alguns dados servem como ilustração de uma ruptura definitiva do antigo paradigma do mercado de trabalho Dupas, (1999) e da cidadania regulada pela inclusão no trabalho 
formal Santos (1979). Segundo a OIT, na América Latina, o setor informal situa-se entre $40 \%$ e $70 \%$ do mercado de trabalho, com uma taxa de crescimento anual superior a $4 \%$. No Brasil, em apenas uma década, a ocupação predominante alterou-se de formal para informal, atingindo no final de 1998 a proporção alarmante de 55\% da força de trabalho metropolitana Pochmann, (1999). O número de empregos gerados com carteira assinada passou de um crescimento de 23\% (1986-1990) para uma queda de 28\% (1991-1997). Estima-se hoje que, de dez novos empregos criados, apenas dois são assalariados do mercado formal, enquanto até a década de 80 a proporção era de oito para dez. A perda de um posto de trabalho no setor formal determinou uma queda no rendimento médio do trabalhador entre 30\% a $40 \%$. A partir dos anos 80 , o desemprego duplicou: de 9\% para 18\%. Entre 1989 e 1996, cresceu relativamente sobretudo nas pessoas com mais de 11 anos de escolaridade, nos homens com idade superior a 40 anos e na população negra. Tornou-se menos grave para aqueles com menor grau de escolaridade, para as mulheres e para os que buscam um reemprego. É uma conseqüência, em certa medida contraditória, da mudança da qualidade dos postos de trabalho gerados.

Outro fato importante a ser destacado foi o declínio da participação relativa dos trabalhadores mais jovens, na faixa de até 29 anos, no total da população empregada. Entre os anos 1980 e 1995 , caiu de $53,1 \%$ para $37,9 \%$ Pochmann, (1999).

A ampliação do desemprego e das ocupações precárias na última década colocam em questão as políticas de geração de emprego e renda. A estruturação do mercado de trabalho durante o ciclo de industrialização nacional caracterizou-se por grande expansão do assalariamento com registro, reduzido desemprego, grande heterogeneidade dos postos de trabalho com diferenças salariais e predominância de baixos salários, junto com informalidade da mão-de-obra e subemprego. Nos anos 90, entra-se numa fase de baixos investimentos produtivos e de crescimento da população, sem uma política favorecedora da ocupação, sem um projeto consistente de reforma agrária capaz de criar empregos no setor primário e de agroindústria e sem políticas adequadas de bem-estar social.

Apesar de dispor de um parque industrial complexo e diversificado, dos mais avançados da periferia do capitalismo, na conjuntura atual, o Brasil carece, ao menos, de uma política de geração de empregos que, por um lado, incorpore a mão-de-obra excedente e de baixa escolaridade na construção de infra-estrutura material - habitação, saneamento básico, transporte, portos - e, por outro, a mãode-obra de maior qualificação no âmbito dos serviços públicos - saúde, educação, turismo e lazer, assistência social. Conseguir-se-iam, dessa forma, alguns dos suportes requeridos para desenvolver as potencialidades do mercado interno e melhorar a distribuição de renda.

\section{A premência de um novo estado}

Conforme Dupas, "as questões centrais envolvendo o futuro das relações entre a sociedade e os Estados nacionais estarão relacionadas à capacidade destes Estados para assumir eficientemente um novo papel indutor-normativo-regulador, ao mesmo tempo em que essas sociedades consigam encontrar alternativas de como lidar com as tendência de crescente exclusão social decorrente do atual modelo econômico global" Dupas (1998).

O walfare state, fundado na expectativa de que o Estado poderia harmonizar a propriedade privada dos meios de produção com a gestão democrática da economia, entrou em crise. Isentando-se da tarefa de regulador do mercado, deixou de fornecer as bases para um compromisso de classe, sustentado no pleno emprego e na redistribuição de renda, descurando-se ainda como provedor de serviços sociais e mediador dos conflitos. O dilema atual reside em como garantir certa proteção social às crescentes populações marginalizadas, quando os recursos orçamentários destinados a essa finalidade tornam-se escassos, em virtude das restrições anteriormente apontadas e, particularmente, do primado absoluto atribuído ao mercado.

O questionamento da visão keynesiana vem simplificando soluções em duas vertentes. Uma, que aposta na criação de um Estado mínimo, sem interferência nas regras do livre mercado, apoiada na justificativa de sua ineficiência e na redução dos orçamentos públicos. Aos governos caberia unicamente o monopólio da defesa e das armas, a garantia da manutenção das leis, da ordem, da justiça e da segurança, bem como o estabelecimento de regras básicas que permitissem aos agentes eco- 
nômicos se movimentarem. Em oposição, pressiona-se por um Estado forte disposto a lidar com os conflitos próprios da globalização, entre os quais aqueles gerados pela exclusão social.

O próprio Banco Mundial mudou recentemente sua concepção liberal da função do Estado, afirmando a inviabilidade do desenvolvimento social e econômico sustentável sem um Estado atuante - e não um Estado mínimo - enquanto parceiro e facilitador World Bank (1997). Nessa mesma direção, a Organização Internacional do Trabalho insiste na importância do papel do Estado, contrariando os economistas que chegam a insinuar a substituição do governo pelo mercado. Avalia que as intervenções do governo não podem ser vistas como contrárias à operação dos mercados, nem a expansão dos mercados pode ser percebida como prejudicial à efetividade das ações governamentais. A redução das dimensões do Estado pode ameaçar a manutenção do comércio em escala global. O que se precisa é de grandes governos ILO (1997-1998).

Esse novo Estado, indutor-normativo-regulador atuante, teria como intransferível missão viabilizar serviços públicos essenciais - saúde, educação, habitação e amparo contra a exclusão social - para a população mais vulnerável social e economicamente. Um Estado capaz de estabelecer políticas compensatórias para frear o aumento do desemprego; de promover a redução das desigualdades, a melhor redistribuição de oportunidades; o desenvolvimento de proteções sociais e estratégias específicas para as populações que sofrem de um déficit de integração e possivelmente sejam inintegráveis.

Em decorrência dessas mudanças, o sistema de Seguridade Social necessitaria de uma readequação. A previdência pública está em declínio, foi projetada para realidades muito diferentes das atuais. $O$ desequilíbrio financeiro ocasionado pelo aumento da expectativa de vida, aliado à queda nas contribuições previdenciarias em função das perdas salariais, ao crescimento do desemprego e do mercado informal explicam, em parte, a crise em curso. A solução introduzida, em alguns países latinoamericanos, de delegar a administradoras privadas o gerenciamento dos fundos de pensão, através de sistemas de capitalização individual, vêm sendo fortemente questionada. Além de submeter a pensão dos segurados à dependência do montante de arrecadações e às flutua- ções do mercado financeiro, essa alternativa contropõe-se aos princípios solidários que fundamentam a seguridade social. É imperativo estabelecer um novo contrato social, negociado de forma ampla com todos os segmentos da sociedade civil e que, do ponto de vista securitário, abranja todos os que podem - e devem - trabalhar e garanta o indispensável socorro àqueles que não podem ou estão dispensados de tal exigência por razões legítimas.

\section{A violência: uma resultante}

$\mathrm{O}$ aumento das desigualdades sociais adquire significações próprias, com algumas semelhanças em relação aos primórdios da revolução industrial, quando a nascente classe operária constituía uma ameaça à estabilidade social. Atualmente, as relações industriais de produção não ocupam um lugar central de conflito estrutural inerente ao antagonismo capitaltrabalho. O foco das situações de dominação e das manifestações de resistência do movimento operário frente a um adversário comum deslocou-se. No presente, o embate deriva-se de diversas formas de exclusão social e conduz a uma violência difusa, forjada no cruzamento do social, do político e do cultural, que se associa a um estado de desagregação, de decomposição social, de individualismo crescente. Na expressão de Wieviorka (1997), representa mais uma violência infrapolítica atribuível ao enfraquecimento de um Estado freqüentemente corrompido, ineficaz, deslegitimado, em virtude de suas próprias carências e das práticas inerentes ao crime organizado. Mesmo a criminalidade mais banal, porém crescente, desenfreada, não emerge de conflitos sociais e políticos abertos.

A anomia suscita violência sem projeto, devastadora e autodestruidora, difícil de controlar à medida em que não há um terreno de negociação, com o risco de explosões nas zonas de fragilidade urbana. A violência moderna reflete "a impossibilidade para o ator de estruturar sua prática em uma relação de troca mais ou menos conflitiva. Ela expressa a defasagem ou o fosso entre as demandas subjetivas de pessoas ou grupos, e a oferta política, econômica, institucional ou simbólica. Ela traz a marca de uma subjetividade negada, arrebatada, esmagada, infeliz, frustrada, o que é expresso pelo ator que não pode existir enquanto tal. Ela é a voz do sujeito não reconhecido, 
rejeitado e prisioneiro da massa desdenhada pela exclusão social e pela discriminação racial" Wieviorka, (1997).

Em cidades como Rio de Janeiro, as desigualdades sociais são demarcadas por fronteiras cada vez menos imateriais. Surge um apatheid urbano-social com configurações geográficas diferentes. Muros e grades sinalizam, além da defesa, a separação. Contraditoriamente, a rígida divisão do espaço urbano privado, com a intenção de evitar a violência, acaba por estimulá-la, tornando os espaços públicos, onde essa divisão é inviável, cada dia mais perigosos. Por outra parte, a veloz expansão, nas grandes metrópoles, de atividades à margem da legalidade vem extrapolando os limites convencionais da economia informal e favorecendo, direta ou indiretamente, a escalada da violência. E mais uma vez, a maioria das vítimas se encontra entre os excluídos.

\section{Violência e saúde pública}

A problemática da violência social, sob o ângulo da saúde pública, vem adquirindo destaque nas agendas das organizações internacionais da área e tornando-se objeto de estudos particulares e regionais no Brasil. Minayo (1994) fez uma síntese do estado da arte, apontando a necessidade de ampliar o campo de investigação e implementar propostas de ação e intervenção nos serviços de saúde. Nessa perspectiva, tentamos contribuir para uma melhor especificação dos agravos incluídos no grande grupo de Causas Externas (E800-E999) da Classificação Internacional de Doenças (CID), partindo do pressuposto que os referentes ao trabalho, além de insuficientemente registrados, não se encontram contemplados em toda a sua abrangência.

Uma das principais barreiras para reduzir a reconhecida subnotificação é a visão securitária que pauta o registro de dados sobre doenças e acidentes de trabalho, inclusive nas informações de notificação compulsória coletadas nos serviços de saúde. Sob essa lógica de concessão de benefícios referentes ao seguro de acidente de trabalho, o universo é composto apenas por trabalhadores com vínculos formais e estão excluídos, dentre eles, os servidores públicos das três esferas de governo, sujeitos a regimes próprios de previdência, os trabalhadores domésticos e os autônomos. Ao que cabe acrescentar, entre outras razões, a concepção ainda dominante de doença ou acidente restrita aos danos físicos; o descompromisso das empresas, particularmente com trabalhadores terceirizados, ao omitir acidentes que não se traduzem em benefícios previdenciários e as estratégias da própria seguridade social de descaracterizar doenças relacionadas ao trabalho ou do trabalho, no já reduzido quadro de classificação. O caso das lesões por esforços repetitivos - LER - é hoje o mais sintomático dessa política de evitar custos.

Trata-se, concomitantemente, de verificar a procedência das interpretações existentes sobre a redução do número de acidentes, que além de atribuí-la à subnotificação, incluem como outros determinantes a introdução de mudanças tecnológicas, os investimentos em medidas de segurança, bem como a terceirização e a informalização, mesmo no mercado formal, das atividades de risco.

O estudo tem como premissa básica a necessidade de ultrapassar a noção de acidente em geral, uma vez que corresponde à agregação de diferentes fenômenos associados à inter-relação entre o trabalhador, seu trabalho e alguma forma de agravo à saúde. Essa denominação ampla é funcional apenas no âmbito dos direitos individuais do acidentado. As doenças agudas, as crônicas e os traumas decorrentes do trajeto ou de situações de risco presentes no ambiente de trabalho confundem-se numa casuística que envolve uma variedade de eventos genericamente qualificados como acidentes de trabalho.

Uma distinção inicial diz respeito aos acidentes típicos e aos relacionados à violência. Nos primeiros, os mais estudados, principalmente no setor secundário da economia, interpretam-se as condições geradoras de eventos acidentários, a partir da análise dos componentes técnicos e organizacionais dos processo de trabalho. No segundo tipo, o procedimento analítico é mediado pelas especificidades do espaço público urbano.

\section{Estratégias da investigação}

Adotamos algumas formas de aproximação, reveladoras das manifestações atuais do quadro anteriormente apresentado, que se encontram em estágios diferentes de desenvolvimento. A lógica construída teve como premissa transpôr as limitações já referidas dos sistemas de registro e empreender investigações 
junto a setores mais expostos a situações de risco. Para a identificação de eventos acidentários no setor informal, distinguimos, através de variáveis construídas, as ocorrências por causas externas capazes de configurar-se como decorrentes do trabalho. $\mathrm{Na}$ análise, a rua - enquanto locus de sobrevivência e de exposição à violência em suas diversas faces - constituiu-se em referencial prioritário.

Apresentamos, a seguir, um esboço de três das estratégias utilizadas e em andamento: em serviços públicos de saúde, junto a adolescentes em situações extremas de risco e uma análise de ocorrências em delegacias policiais.

\section{Busca ativa em serviços públicos de saúde}

Consideramos que os serviços públicos de saúde representam uma primeira fonte potencial de informações, por serem, em princípio, acessíveis ao conjunto dos trabalhadores, e talvez os únicos para aqueles com vínculos precários. Destacam-se com esse propósito, particularmente, os hospitais de maior complexidade, dotados de serviço de emergência, setores de internação e ambulatórios especializados. A coleta de dados nos Boletins de Emergência (BE) em dois desses hospitais, complementada por entrevistas com pacientes internados em enfermarias, permitiu avaliar sua potencialidade.

Realizamos um trabalho de campo preliminar para observar o atendimento a pacientes que recorreram aos setores de emergência. Tal atividade foi reveladora inicial das trilhas por onde se perde o registro dos Acidentes de Trabalho (AT). Os casos são identificados pelo funcionário da recepção que preenche o cabeçalho do BE. Se o paciente refere que o evento relaciona-se ao trabalho e tem carteira assinada, é colocado o carimbo "AT", o que a priori já exclui os trabalhadores do setor informal. Os que pertencem ao setor formal são orientados a anotar o número do BE e a procurar posteriormente o setor de registro de dados. Ocorre, com freqüência, que muitos pacientes, mesmo do setor formal, não identificam como AT os acidentes de trajeto. Observamos ainda que, tratando-se de acidentes de menor gravidade, quando atendidos e liberados por acadêmicos, a ausência de assinatura de um médico no BE subtrai o valor legal do documento. Em nenhuma sala de atendimento, é rotina a identificação de AT. Assim, se ela não ocorre na re- cepção e o paciente não anota o número do $\mathrm{BE}$, prática generalizada, o resgate do evento para posteriores reivindicações de direitos trabalhistas exige um longo percurso. Em síntese, é a lógica previdenciária exclusivamente, quando respeitada, que orienta os registros.

Nas duas Unidades - Hospital Municipal Miguel Couto (HMMC) e Hospital Municipal Souza Aguiar (HMSA) - selecionamos para análise os casos de pacientes com idade acima de 5 anos e vitimados por causas externas no período de uma semana. Do total de causas externas registradas nesse período, 1155 no HMMC e 1250 no HMSA, o número de acidentes de trabalho identificados foi de 63 $(5,5 \%)$, no primeiro, e 67 (5,4\%), no segundo.

As lacunas e deficiências no preenchimento de campos do BE capazes de sinalizar eventos relacionados ao trabalho, mesmo que não registrados, tais como profissão da vítima, causa eficiente da lesão e o local da ocorrência - só preenchidos, respectivamente, em $0,7 \%, 33 \%$ e $1,4 \%$ dos casos - limitou as expectativas quanto a essa estratégia que parecia promissora. No entanto, algumas constatações puderam ser feitas. Nos dois hospitais, no período de 8 às $18 \mathrm{~h}$, verifica-se um significativo aumento nos agravos por causas externas e é nesse horário que ocorre o maior registro de AT: 77,8\% no HMMC e 64,2\% no HMSA do total de acidentes identificados como tal. Os boletins do HMMC revelam a concessão de 98 dispensas a pessoas que supostamente tinham vínculos de trabalho, mas em apenas 18,4\% dos casos associavam-se à identificação de AT.

$\mathrm{Na}$ tentativa de superar as deficiências apontadas, procedemos, no período de um mês, a um levantamento de todos os pacientes internados nas enfermarias de quatro serviços do HMSA, considerados os mais indicados para a finalidade da investigação: cirurgia geral, cirurgia pediátrica, neurocirurgia e ortopedia.

Através da análise dos dados contidos nos prontuários desses pacientes, complementados com as informações existentes no serviço social, foram selecionados, para entrevista posterior, os vitimados por causas externas.

Dos pacientes internados (384) no período da pesquisa, 108 casos correspondiam a causas externas. Devido à recusa ou empecilhos de outra natureza, foram entrevistados 98 desses pacientes. Quando apresentavam dificuldades ou impossibilidade de comunicação, recorreu-se à ajuda de seus acompanhantes. 
Ao comparar os dados quantitativos obtidos nas entrevistas com os registrados nos prontuários, evidenciam-se as elevadas proporções da subnotificação. Foram caraterizados 31 AT, enquanto o Hospital identificou apenas 5, mesmo assim em decorrência da iniciativa dos próprios trabalhadores em informar o AT no atendimento inicial, do uso do uniforme da empresa e da interferência de um participante deste estudo que alertou para o registro na sala de emergência. Em nenhum prontuário constava sequer a profissão do paciente e sua permanência na enfermaria não contribuiu para novos registros, embora diversos casos fossem do conhecimento da equipe médica. Tais omissões refletem a falta de orientação quanto à importância do registro de eventos acidentários originados nas atividades laborais e, por razões de natureza diversa, a própria cultura dos serviços.

A precariedade dos vínculos apresenta-se de forma diferenciada. Entre os acidentados internados nas referidas enfermarias, 15 tinham carteira de trabalho assinada; 4 realizavam, com vínculo informal, atividades próprias do mercado formal - inclusive com permanência de até 7 anos - 12 eram trabalhadores autônomos e 5 realizavam trabalhos eventuais.

Dos 26 AT não registrados, 11 referiam-se a trabalhadores com carteira assinada e, em alguns casos, a própria empresa já havia reconhecido o acidente. Nesse fato combinam-se a lógica omissa de registro hospitalar e a própria compreensão dos trabalhadores. Muitos daqueles com carteira assinada, até com mais de 20 anos de serviço, não identificam o acidente que ocorre fora do local de trabalho, e os que têm vínculos informais não demonstram interesse na identificação, por não redundar em benefícios previdenciários. Apenas restringem-se a apontar a tragédia que o episódio representa para a manutenção da família. Em determinadas situações, a maior preocupação reside no ressarcimento dos danos pessoais e materiais sofridos, entre as quais expressam-se inclusive manifestações de vingança. A imensa maioria dos eventos relacionados à violência urbana encontrados nas enfermarias ocorreram com trabalhadores que exerciciam atividades informais, os mais expostos e desprotegidos socialmente.

A introjeção da culpa pessoal permeia as interpretações dos acidentes típicos, seja no setor formal ou informal, mesmo relativizada algumas vezes pela referência a injunções de diversas ordens, como não prejudicar a produção ou garantir o emprego. Embora apareça como razão do acidente a falta de treinamento e de políticas e práticas de segurança, como o uso de equipamentos deteriorados, o fatalismo implícito nas falas insinua a aceitação dos riscos como inerentes ao trabalho. Contrariamente, nos eventos derivados da violência, culpa-se o agressor direto ou, de modo mais amplo, a ausência de segurança pública, com a seqüente e flagrante decepção de não visualizar instâncias às quais recorrer.

A perspectiva para os que têm direitos garantidos é o retorno ao trabalho, embora alguns demonstrem incerteza quanto à sua continuidade, temam ficar incapacitados ou externem a intenção de mudar de emprego. Para os informais, instaura-se a preocupação com a sobrevivência do núcleo familiar e o constrangimento diante da dependência econômica de parentes. Em certos casos, a inexistência de expectativas é tão marcante que aderem ao presente, enfatizando a sorte de não terem morrido. Em outros, após o confronto com a adversidade, percebe-se até um otimismo diante da vida, a esperança de encontrar saídas, e o veemente descarte da possibilidade de outro acidente.

O Sistema de Informações de Mortalidade (SIM) do Ministério da Saúde, construído pela compilação dos atestados de óbito, em tese, constituiria o maior banco de dados para identificar e especificar os acidentes fatais. Apresenta, entretanto, uma série de lacunas, para cuja superação se torna necessário adotar determinados filtros: idade; ocupação; qualificação, entre outros. Os investimentos que vimos realizando para dar continuidade a estudo anterior de Machado (1991) ainda não se concretizaram em resultados significativos. De qualquer forma, para inferir conclusões mais expressivas a partir dos atestados de óbito, será preciso efetuar pesquisas qualitativas. Como demonstrou Mendes (1991), em estudo dessa natureza realizado em Porto Alegre, num período de três meses, em 99 casos de óbito por causas externas, foram encontrados 18 AT, quando nos atestados constavam apenas $3 . \mathrm{Na}$ sua imensa maioria, as vítimas exerciam trabalho precário e os acidentes ocorreram na via pública. As famílias entrevistadas acrescentaram ao sofrimento decorrente da subtração de uma vida pela violência, a negação de amparo social que reduzisse, pelo menos, os efeitos da perda de um aporte financeiro fundamental para sua sobrevivência. 


\section{Adolescentes em situações extremas de risco}

Hoje, ao dimensionar os impactos da violência em trabalhadores do mercado informal, evidencia-se a vulnerabilidade da população adolescente atingida de forma acelerada, sobretudo nos últimos dez anos. Segundo dados do Ministério da Saúde, na década de 90, constatou-se um aumento significativo das mortes de adolescentes, na faixa de 15 a 19 anos, ocasionadas por homicídios. Em 1995, a mortalidade por causas externas nessa população atingiu $78.32 \%$ do total das mortes, sendo $33.19 \%$ correspondente a homicídios.

Os estudos realizados pelo Centro LatinoAmericano de Estudos sobre Violência e Saúde - Claves, da Fiocruz, no município do Rio de Janeiro, confirmam esse crescimento expressivo. De 1980 a 1994, a mortalidade por causas externas nesse grupo subiu de 169.5 por 100.000 habitantes, em 1980, para 177.5 em 1994, majoritariamente no sexo masculino, ficando a taxa de homicídios em 62.2\%. Já em 1995, as taxas de mortalidade por causas externas e por homicídios atingiram, respectivamente, 188.3 e 108.7. Como agravante, depara-se com o fato de que $47.1 \%$ das mortes por causas externas, na faixa de 10 a 19 anos, inclui-se no grupo de lesões ignoradas Souza \& Minayo (1995).

Não é descabido supor que, entre tais causas de configuração nebulosa, situam-se as relacionadas a circunstâncias que dificultam ou impedem o esclarecimento das causas de óbitos e agravos. Desde as que envolvem as conseqüências de atividades à margem da legalidade às que decorrem do exercício de ocupações não reconhecidas socialmente, embora componham, no anonimato de seus atores, o cenário cotidiano das grandes cidades.

Alguns indícios das causas proveniente da rede de violência inerente ao narcotráfico foram obtidos em estudo de caso, de cunho eminentemente qualitativo, sobre mortalidade de adolescentes inseridos nesse mercado, em uma favela do Rio de Janeiro com 15.000 habitantes Meirelles (1998). Os resultados, por si mesmos, são alarmantes. Somente, no ano de 1997, ocorreram 57 homicídios que atingiram cerca de $27 \%$ dos adolescentes diretamente envolvidos no narcotráfico. Tais dados, obviamente não figuram nas estatísticas sobre acidentes de trabalho e, por motivos distintos, é bastante provável que permaneçam ocultos ou não relacionados a suas verdadeiras origens.
Os próprios veículos de imprensa que cobrem homicídios dessa natureza noticiaram, para todo o estado, números que apenas se aproximam do dobro do constatado na favela estudada. Assumimos como tarefa conseguir, minimamente, estimativas dessa casuística, no âmbito do município do Rio de Janeiro e de outros de grande porte, capazes de dar maior visibilidade a essas mortes anônimas.

Esse cenário reflete as conseqüências da captura de adolescentes por uma alternativa de trabalho ausente do amplo leque de atividades incluídas na literatura sobre o mercado informal. No entanto, o processo e a organização desse trabalho ilegal lhe conferem características similares às presentes nas atividades laborais. As diversas funções exercidas, inclusive sob extremo autoritarismo, geram, de forma diferenciada, situações de risco iminente de vida.

Pensar em estratégias preventivas impõe desvendar os diversos ângulos dessa problemática - vinculada, mas não restrita, à situação de pobreza de caráter geral - que, sem ignorar sua complexidade, certamente guarda relação com as oportunidades de inclusão social sistematicamente negadas a esse segmento da população. Remete, ainda, à análise das propostas/programas de organizações governamentais e não-governamentais tendentes a inibir a atração por esse mercado que não se reduzam à prática repressiva oficial.

\section{Análise de registros de ocorrências policiais}

Os registros de ocorrência da polícia civil representam também um acervo valioso que evidencia grande parte da violência social de que são vítimas os trabalhadores no seu percurso pela cidade e inclusive no próprio local de trabalho. A investigação em andamento nas delegacias apresenta limitações devido à descrença da população em recorrer a essa instância. Estima-se que apenas $20 \%$ das pessoas vitimadas comuniquem a ocorrência, quando o intuito é o de tramitar processos judiciários ou securitários. Esse investimento vem demonstrando que os registros policiais confirmam a exclusividade de uma visão previdenciária, inclusive mais restrita, ao reconhecer apenas os acidentes típicos, ocorridos nos próprios locais de trabalho. No entanto, permite dar visibilidade às diversas expressões de violência urbana que afetam à população trabalhadora 
e ultrapassam a concepção da legislação previdenciária que considera acidente de trabalho o ocorrido durante o exercício da atividade laboral (acidente típico) ou nos deslocamentos da ou para a residência ou local de refeição (acidente de trajeto), provocando lesão corporal ou perturbação funcional que leve à morte, perda ou redução permanente ou temporária da capacidade para o trabalho. Constatamos agressões, assaltos, roubos, colisões, em dimensões diferenciadas, que causam transtornos, não necessariamente de ordem física, mas nem por isso menos aflitivos que os dessa natureza, e a usurpação de instrumentos ou meios de trabalho, com a conseqüente interrupção de ganhos, gerando situações de constrangimento e ameaça, com prováveis implicações psíquicas. Em termos quantitativos, alguns dados interpretados até o momento mostram a predominância absoluta dos efeitos da violência no setor de serviços ( $84 \%$ das ocorrências) e o reduzido número de acidentes de trabalho registrados (1,3\% do conjunto de eventos). Em virtude das razões alegadas anteriormente para que a população recorra a essa instituição, não foi possível detectar, de modo mais preciso, a influência das formas de precarização do trabalho no conjunto de eventos analisados.

\section{Referências}

Arendt H 1990. Origens do Totalitarismo. Companhia das Letras, São Paulo, 562 pp.

Caire G 1997. Normalisation des elplois atypiques, p. 239-252. In Iresco - Institut de Recherche sur les Societés Contemproraines - Précarisation Sociale, Travail et Santé. Iresco, Paris.

Castell R 1998. As Metamorfoses da Questão Social: uma Crónica do Salário. Vozes, Petrópolis, 611 pp.

Dupas G 1999. Economia Global e Exclusão Social: Pobreza, Emprego, Estado e o Futuro do Capitalismo. Paz e Terra, São Paulo, 219 pp.

Escorel S 1998. Vidas ao Léu: uma Etnografia da Exclusão Social. Tese de Doutorado. Universidade de Brasília. Brasília. 307 pp.

Forrester V 1997. O Horror Econômico. Unesp, São Paulo, 154 pp.

International Labor Organization 1997-98. Industrial Relations, Democracy and Social Stability. World Labor Report, Genebra.

Machado JMH 1991. Violência no Trabalho e na Cidade: Epidemiologia da Mortalidade por Acidentes de Trabalho Registrados no Município do Rio de Janeiro em 1987 e 1998. Dissertação de Mestrado. Escola

\section{Considerações finais}

Este texto procurou sistematizar sucintamente o que hoje se entende por precarização do trabalho e apontar sua relação com os processos de exclusão e violência social. Num segundo momento, buscou ilustrar, com relatos de investigação, as lacunas, a também precariedade dos sistemas de informação, particularmente nos serviços públicos de saúde, para o reconhecimento da morbidade e mortalidade por acidentes de trabalho, em sua magnitude e especificidade, com ênfase nos relacionados à violência urbana.

Em última instância, essa reflexão assinala a necessidade inadiável de desvendar esse universo problemático da precarização e do não-trabalho. Encontramo-nos diante de um habitus diferente de ser-no-mundo, de uma mutação na sociedade salarial historicamente construída, onde o trabalho representava o principal fundamento da cidadania e um dos poucos vínculos de reconhecimento que a população trabalhadora alcançou no país. A nova questão social alia-se a antigos dilemas, ainda não ultrapassados, e emerge, por afetar as condições gerais de existência, como desafio para os que investigam e atuam no âmbito da saúde coletiva.
Nacional de Saúde Pública, Fundação Oswaldo Cruz, Rio de Janeiro, 312 pp.

Mendes JMR 1999. O Verso e o Anverso de uma História: o Acidente e a Morte no Trabalho. Tese de Doutorado. Pontifícia Universidade Católica, São Paulo, 293 pp.

Meireles ZV 1998. Vida e Trabalho de Adolescentes no Narcotráfico numa Favela do Rio de Janeiro. Tese de Mestrado. Escola Nacional de Saúde Pública, Fundação Oswaldo Cruz, Rio de Janeiro, 101 pp.

Minayo MCS 1994. A violência social sob a perspectiva da saúde pública. Cadernos de Saúde Pública 10 (suplemento): 7-18

Pochmann M 1999. O Trabalho sob Jogo Cruzado. Contexto, São Paulo, 205 pp.

Santos WG 1979. Cidadania e Justiça. Campus, Rio de Janeiro.

Souza ER, Minayo MCS 1995. O impacto da violência sobre a saúde, p. 87-116. In MCS Minayo (org.) Os Muitos Brasis: Saúde e População na Década de 80. Hucitec, São Paulo.

Wieviorka M 1997. O novo paradigma da violência. Tempo Social, Revista Sociol. USP 9(1): 5-41.

World Bank 1997. The State in a Changing World. World Development Report. Washington. 